\title{
Eye signs for the neurologist in the Intensive Care Unit
}

\author{
Umaiorubahan Meenakshisundaram Sreenivas ${ }^{1}$, P.R. Prabash ${ }^{2}$, \\ Umaiorubahan Meenakshisundaram ${ }^{2}$ \\ ${ }^{1}$ Institute of Neurology, Madras Medical College, Chennai, India \\ ${ }^{2}$ Apollo Hospitals, Chennai, India
}

\begin{abstract}
Introduction. The eyes are a window to the brain' is a maxim that holds true especially in the intensive care setting. Recognising specific eye signs aids rapid decision-making regarding diagnosis or prognosis. Eye signs play a pivotal role in intensive care for the neurologist.

State of the art. Eye signs have long been considered the best clinical clue for assessment of a comatose patient. In critically ill patients, the recognition of brainstem involvement hinges primarily on eye signs. The ability to recognise and interpret these signs goes a long way towards ensuring proper care of neurological illness in intensive care units.

Clinical implications. In this article we enumerate the various signs to be assessed in the ocular and periocular structures. We look at the various types of nystagmus and abnormal eye movements which help to localise lesions in the brainstem. This will aid better diagnosis and prognostication. We categorise eye signs as Category 1 or 2 according to whether they are periorbital and ocular signs or oculomotor abnormalities. Category 2 signs are further sub-classified into Category $2 \mathrm{a}-$ common and Category $2 b$ - uncommon.

Future directions. Clinical anatomical correlation of specific signs such as ocular dipping has yet to be elucidated. Research that looks into specific eye signs may help with better anatomic correlation and localisation of lesions.
\end{abstract}

Key words: eye signs, nystagmus, coma, intensive care, pupil, oculomotor abnormalities

(Neurol Neurochir Pol 2019; 53 (6): 402-407)

\section{Introduction}

Just as the 'face is the index of the mind', to a neurologist the eyes are the window to the brain. This is especially true in the setting of acutely ill patients encountered in the intensive care unit. Eye signs can be of diagnostic, prognostic and therapeutic value.

The key is to spend some time observing the eyes because some signs can be made out only on examination lasting for at least a few minutes (up to five minutes for some) as this is likely to be rewarding and exciting.

The eye signs in the ICU of interest to a neurologist can be divided into two broad categories (Tab. 1,2):

1. signs involving the periorbital, ocular structures including the pupils, eyelids, conjunctivae, lens and cornea

2. signs of eye movement abnormalities - paresis and abnormal movements. This review, primarily emphasising the clinical value of eye signs, will focus on this category of
Table 1. Localisation of pupillary abnormalities

\begin{tabular}{ll}
\hline Pupil size and location & Site of lesion \\
\hline small and reactive & Diencephalon \\
Midposition and fixed & Midbrain \\
Dilated and fixed, down and out & $3^{\text {rd }}$ cranial nerve \\
Large and fixed & Tectal \\
Pinpoint & Pons \\
Small and reactive & Metabolic
\end{tabular}

signs because a detailed enumeration of the first category is beyond the scope of this article.

The second category can be further divided into:

2a. common signs including gaze preferences, deviations, dysconjugate eyes, and common types of nystagmus 
Table 2. Categorisation of eye signs

\begin{tabular}{|c|c|c|}
\hline & Sign & Interpretation \\
\hline \multirow[t]{7}{*}{ Category 1} & Exophthalmos & Retrobulbar lesion, thyrotoxicosis, sphenoid wing mass \\
\hline & Periorbital echymoses & Base of skull fracture \\
\hline & Conjunctival congestion & $\begin{array}{l}\text { Caroticocavernous fistula, bleeding diatheses, endocarditis, } \\
\text { trigeminal autonomic cephalgia }\end{array}$ \\
\hline & Band Keratopathy & Hypercalcemia \\
\hline & Kayser Fleischer ring & Wilson's disease \\
\hline & Ptosis & Myasthenia gravis, $3^{\text {rd }}$ nerve palsy, Horner's syndrome \\
\hline & Pupillary changes & Brainstem \\
\hline \multirow[t]{21}{*}{ Category $2 a$} & Down and out eye & $3^{\text {rd }}$ cranial nerve palsy \\
\hline & Down and out with dilated pupil & Posterior communicating artery aneurysm \\
\hline & Down and out with spared pupils & Ischaemic $3^{\text {rd }}$ nerve palsy \\
\hline & $\begin{array}{l}\text { Down and out with contralateral superior rectus } \\
\text { weakness }\end{array}$ & $3^{\text {rd }}$ nerve nuclear lesion \\
\hline & Extorted and elevated eye & $4^{\text {th }}$ nerve palsy \\
\hline & Opposite head tilt & $4^{\text {th }}$ nerve palsy \\
\hline & Lateral head turn & $6^{\text {th }}$ nerve palsy \\
\hline & Complex ophthalmoplegia & Dysthyroid state, mitochondrial disorders, myasthenia \\
\hline & Internuclear ophthalmoplegia & Medial longitudinal fasciculus \\
\hline & One and a half syndrome & MLF and PPRF \\
\hline & Gaze preference & $\begin{array}{l}\text { Supratentorial - I/L, } \\
\text { Brainstem - C/L }\end{array}$ \\
\hline & Down and in eyes & Thalamus, upper midbrain \\
\hline & Wrong way eyes & Medial thalamic haemorrhage \\
\hline & Skew deviation & Lesion on side of hypotropic eye \\
\hline & Upbeat nystagmus that increases in upgaze & Cerebellar vermis \\
\hline & Upbeat nystagmus that decreases in upgaze & Medulla \\
\hline & Downbeat nystagmus & Cervicomedullary junction \\
\hline & Rebound nystagmus & Cerebellum \\
\hline & Multidirectional, gaze evoked nystagmus & Cerebellum \\
\hline & Unidirectional, mixed nystagmus & Peripheral vestibular apparatus \\
\hline & Direction changing nystagmus & Lateral medulla \\
\hline \multirow[t]{10}{*}{ Category $2 b$} & Convergence retraction nystagmus & Periaqueductal grey \\
\hline & Ocular flutter & Dentate nucleus \\
\hline & Opsoclonus & Infectious / parainfectous / paraneoplastic \\
\hline & Ocular bobbing & Pons \\
\hline & Ocular dipping & Brainstem \\
\hline & Seesaw nystagmus & Sellar / parasellar masses \\
\hline & Periodic alternating nystagmus & Nodulus \\
\hline & Oculogyric crisis & Postencephalitic parkinsonism / drug-induced \\
\hline & Roving eyes & Light coma \\
\hline & Ping-pong eyes & Bihemispheric dysfunction \\
\hline
\end{tabular}

2b. uncommon/ominous signs including ocular flutter, opsoclonus, ocular bobbing, ocular dipping and a few others. This article will then discuss ocular manifestations of stroke and of brain death. It is intended as a guide to the clinician when eye signs are encountered in the Intensive Care Unit.
Category 1 signs can be:

I. Exophthalmos (unilateral) - causes include thyroid eye disease, orbital mass lesion, orbital pseudotumour, cavernous sinus thrombosis, carotid cavernous fistula, meningocele, sphenoid wing meningioma, orbital neoplasm, 
mucormycosis, vascular malformation of the orbit, and neurofibromatosis. Horner's syndrome causes apparent enophthalmos [1].

II. Periorbital ecchymosis (so-called 'raccoon eyes') indicates the presence of basal skull fractures [2].

III. Carotid cavernous fistula can cause tortuous (corkscrew) blood vessels in the conjunctiva. A subconjunctival haemorrhage may indicate bleeding disorders or endocarditis. Conjunctival injection may be a part of trigeminal autonomic cephalalgia, Horner's syndrome [3].

IV. Copper deposition in the Descemet membrane results in hepatolenticular degeneration (Kayser Fleischer ring) [4]. Hypercalcemia secondary to sarcoidosis, hyperparathyroidism, and vitamin D intoxication may result in band keratopathy [5]. Yellow lipid deposits in the eyelids and periorbital skin (xanthelasma), serves as a marker of atheromatous vascular disease. Lenticular opacities may be due to high doses of corticosteroids or sustained high levels of blood glucose, but can be present due to normal ageing as well.

V. Ptosis - in myasthenia gravis is most often asymmetric but can be unilateral, may shift from side to side, characteristically fluctuates from moment to moment. Prolonged upgaze can worsen the ptosis (fatiguable ptosis). Another characteristic sign of myasthenia is Cogan's lid twitch sign; after a period of downgaze when the eyes are suddenly returned to the primary position, there may be a brief overshoot twitch of lid retraction. In curtain sign or seesaw ptosis, manually raising the more ptotic lid causes relaxation, and an eye with less ptosis, sometimes even no ptosis, may suddenly crash (as occipitofrontalis is a single muscle). Another characteristic sign of myasthenia is brief fluttering of the lid margins upon moving the eyes vertically. Ptosis in Lambert-Eaton syndrome may temporarily improve after a brief period of upgaze. Bilateral ptosis may indicate a nuclear $3^{\text {rd }}$ nerve palsy. Blepharospasm may be seen in isolation or as part of dyskinesias and drug-induced movement disorders. When orbicularis oculi is also weak (weakness of both eye closure and opening), this is indicative of a pathology involving the nerves, muscles, or neuromuscular junction. Bilateral ptosis can occur with right hemispheric lesions (and indeed used to be known as cerebral ptosis) [6]. Partial ptosis may be seen in Horner's syndrome.

VI. Pupillary signs include anisocoria ( $3^{\text {rd }}$ nerve palsy, Horner's syndrome), and the different characteristic pupils - Argyll Robertson pupils, Adie's, Marcus-Gunn (RAPD) pupils [7,8]. Pupillary responses in a comatose patient may be:

- bilateral small, reactive - in metabolic encephalopathy, bilateral thalamic or pontine lesions, narcotics, barbiturates,

- bilateral dilated and unreactive - midbrain lesion,

- bilateral dilated and reactive - following a seizure,

- unilateral miosis - thalamus, sympathetic efferents lesion [9].

\section{Category 2}

2a Commonly encountered signs and their significance

- Lesions of $3^{\text {rd }}, 4^{\text {th }}$, or $6^{\text {th }}$ cranial nerves:

Complete $3^{\text {rd }}$ cranial nerve palsy causes ptosis, with an outward and mildly downward eye (unopposed action of the $4^{\text {th }}$ and $6^{\text {th }}$ nerves) with a dilated pupil that has no light response, directly or consensually, or near response. Pupillary function is usually spared in ischaemic lesions. A nuclear lesion of the $3^{\text {rd }}$ cranial nerve may also cause weakness of the contralateral superior rectus [10].

In $4^{\text {th }}$ nerve palsy, there is extorsion and impairment of depression of the adducted eye. The characteristic head tilting to the opposite shoulder is known as Bielschowsky sign.

In $6^{\text {th }}$ nerve palsy, there is impairment of abduction of the affected eye, and the eye deviates medially. The head is turned towards the side of the paretic muscle [11].

Causes of complex ophthalmoplegia are dysthyroid eye disease, myasthenia gravis, and mitochondrial disorders.

- Internuclear ophthalmoplegia

Lesions of the medial longitudinal fasciculus (MLF) cause an internuclear ophthalmoplegia (INO). When, for example, the right PPRF and $6^{\text {th }}$ nerve nucleus act to initiate lateral gaze towards the right, the left medial rectus receives no signal to contract, due to the left MLF lesion. As a result, gaze to the right results in abduction of the right eye but no adduction of the left eye. Typically the abducting eye shows nystagmus. Slowness of the adducting saccades compared to the abducting saccades may be an early sign of an INO due to demyelination, and is a very useful sign for diagnosis. Patients with bilateral INO have been said to have WEBINO syndrome (wall-eyed bilateral INO) [12].

A medial pontine lesion (e.g. on the right) can affect both the right PPRF and the right MLF crossing from the contralateral side. Because of the right PPRF lesion, the patient has a complete horizontal gaze palsy to the right side. Because of the right MLF lesion, the patient has an INO on the right side resulting in adduction failure of the right eye. The only eye movement possible is abduction of the left eye. The constellation of these findings is termed 'one-and-a-half syndrome'. It should be borne in mind that the $6^{\text {th }}$ nerve nucleus has both nuclear and internuclear components and a nuclear $6^{\text {th }}$ palsy can be associated with an INO (and $7^{\text {th }}$ nerve involvement) [13].

- Gaze deviations/preferences

Unilateral frontal lobe seizure activity pushes the eyes to the opposite side. With destructive frontal lobe lesions, the patient is unable to move their eyes contralaterally. This is known as gaze paresis or preferential gaze to the opposite side. The normal PPRF pulls the eyes over, so destructive lesions of the PPRF impair the ability to gaze ipsilaterally, resulting in gaze deviation toward the intact side. Therefore patients with destructive frontal (supratentorial) lesions gaze away from the side of the hemiparesis, while patients with pontine (infratentorial) strokes gaze toward the hemiparesis. 'Downward and inward' eyes indicate a thalamic, upper midbrain lesion. 
'Wrong way eyes' is a term used to denote deviation of the eyes towards the side of weakness of limbs in a supratentorial lesion, and has been described with medial thalamic haemorrhages. This has been attributed to compression of the frontopontine fibres at the level of mesencephalon, irritation of intralaminar thalamic nuclei, and imbalance in the bihemispheric control of pursuit mechanisms [14].

- Skew deviation

In skew deviation there is vertical deviation (malalignment) of one eye above the other that is caused by an imbalance of the vestibular inputs to the oculomotor system. It results from a prenuclear lesion involving the brainstem or cerebellum, and the lesion is usually on the side of the hypotropic eye, except for lesions of the midbrain, where the ipsilateral eye is hypertropic. This is a component of the ocular tilt reaction and is also usually seen with an INO. Skew deviation may sometimes alternate with lateral gaze to either side. This indicates a lesion at the pretectal midbrain or the cervicomedullary junction. They can be differentiated based on associated findings [15].

- Nystagmus

Nystagmus denotes an imbalance and an inability to maintain fixation, resulting in unwanted slow deviation of the eyes followed by a fast deviation in the opposite direction. The abnormality is the slow deviation, although the fast component is used to denote the direction of the nystagmus. Differentiating between central and peripheral causes of nystagmus is paramount in an ICU setting. The central ocular motor signs that are in favour of a central nystagmus are: skew deviation, central fixation nystagmus, saccadic smooth pursuit, gaze-evoked nystagmus contralateral to direction of spontaneous nystagmus, rebound nystagmus, acute vertigo and nystagmus with normal head impulse test, and impaired VOR suppression [16].

In upbeat nystagmus, there is up-beating nystagmus on primary gaze. If the nystagmus increases in upgaze the localisation is in the cerebellar vermis, but if the nystagmus decreases in upgaze, the lesion is in the medulla.

Downbeating nystagmus in primary gaze is downbeat nystagmus, maximal in eccentric and downgaze. The location of the pathology may be the cervicomedullary junction.

Rebound nystagmus is horizontal gaze-evoked nystagmus that changes direction with refixation to the primary position here the pathology is in the cerebellum or cerebellar connections. Nystagmus in posterior circulation stroke:

- Midbrain - convergence retraction, dissociated (INO), rotary (torsional),

- Pons - INO, ocular bobbing (although not exactly a nystagmus),

- Medulla oblongata - may imitate peripheral type,

- Cerebellum - peripheral type, multidirectional gaze-evoked. Lateral medullary syndrome is a treasure trove of eye signs. The characteristic nystagmus is the direction-changing type: horizonto-rotary to one side and horizontal to the other side, i.e. with features of peripheral vestibular dysfunction to one side and a central fixation type on looking to the other side [17].

\section{$2 b$ Uncommon eye signs}

In Parinaud's syndrome, there is impaired upgaze. When patients attempt to look up, the eyes may spasmodically converge and retract backward into the orbits. This phenomenon is known as convergence-retraction nystagmus. This is in fact a misnomer, because there is no slow deviation to start with. Other features include eyelid retraction (Collier's sign) with a poor, rarely absent, light response and much better near response (tectal pupils). This is due to a lesion involving the periaqueductal region [18].

Ocular flutter - intermittent, rapid, back-to-back horizontal saccades causing a quivering movement. Ocular flutter and opsoclonus are a continuum, and the location of the pathology is in the cerebellum or brainstem cerebellar connections, dentate nucleus. They are clinically differentiated by the fact that ocular flutter occurs only in the horizontal plane, while opsoclonus is multiplanar. Opsoclonus consists of involuntary, arrhythmic, chaotic, multidirectional saccades, without intersaccadic intervals. Saccades may be horizontal, vertical, or torsional. It is present during fixation, smooth pursuit, convergence, and persists during sleep or eyelid closure. Opsoclonus differs from nystagmus in that the phase that takes the eye off the target is always a saccade, not a slow eye movement. Opsoclonus may be infective / parainfectious or paraneoplastic, and is likely to be a part of the opsoclonus-myoclonus-ataxia syndrome [19].

Ocular bobbing is a swift downward jerk with slow drift back to the primary position. The patient is often unconscious. These abnormal movements in the vertical plane indicate a lesion involving the horizontal gaze mechanisms, and hence localised to the pons. This needs to be differentiated from a downbeat nystagmus, which starts with a slow deviation upwards. Absent horizontal eye movements in ocular bobbing also helps to differentiate them [20].

Ocular dipping, converse ocular bobbing, and converse ocular dipping are other rare signs that occur with brainstem lesions and diffuse cerebral hemispheric dysfunction [20].

In seesaw nystagmus, there is pendular torsional-vertical oscillation; one eye rises and intorts, the other falls and extorts; this is sometimes associated with bitemporal hemianopia caused by sellar or parasellar masses [21].

Periodic alternating nystagmus is a remarkable horizontal jerking that periodically (roughly every 90 seconds) changes direction, interposed with a brief neutral period during which the eyes show no nystagmus, or a jerk downward. Periodic alternating nystagmus (PAN) is seen with lesions in the nodulus of the cerebellum. PAN can be abolished by the administration of baclofen [22].

Oculogyric crisis refers to attacks of involuntary conjugate upward deviation of the eyes, which may be transient or last for hours, and it is classically associated with postencephalitic parkinsonism. It can also be an acute dystonic reaction caused by dopamine receptor blocking agents [23]. 
Roving conjugate eye movements are characteristic of a light coma [9].

Ping-pong gaze, where slow horizontal ocular deviations shift every few seconds from side to side, is a form of roving eye movement that occurs with bihemispheric infarctions. In a similar phenomenon called 'windscreen-wiper eyes', there is slower, side-to-side pendular oscillation of the eyes. This is also associated with bilateral hemispheric lesions that have presumably released a brainstem pacemaker [9].

The absence of eye movements after VOR and caloric testing is an important step in documenting brain death. Lack of consistent visual following of objects is a sign of vegetative state.

The eye signs in brainstem dysfunction are: loss of spontaneous eye movements; midposition of the eyes; lack of response to oculocephalic and caloric (oculovestibular) testing; and the presence of dilated or midposition fixed pupils (no smaller than $3 \mathrm{~mm}$ ) [9].

\section{Conclusion}

Examination of the eye is one of the most important steps in the assessment of a patient in the intensive care unit. The eye offers important clues in terms of localisation and prognostication. Future research may provide information about the clinical significance and localisation of signs such as ocular dipping and opsoclonus, which as yet do not have a specific anatomical substrate to explain the findings. Even in this age of advanced imaging and electrophysiological examination, clinical examination of the eyes remains a valuable tool in the diagnostic armamentarium of the neurologist.

Ethical permissions: No ethical approval was necessary for the preparation of this article Conflict of interest: None

\section{References}

1. Exophthalmos (Proptosis): Background, Pathophysiology, Epidemiology [Internet]. Emedi-cine.medscape.com. 2018. https://emedicine. medscape.com/article/1218575-overview (30 October 2018).

2. Alaghband $P$, Long V. Periorbital Ecchymosis. The Journal of Pediatrics. 2016;168:245-245.e1.

3. Phan K, Xu J, Leung V, et al. Orbital Approaches for Treatment of Carotid Cavernous Fistulas: A Systematic Review. World Neurosurg. 2016; 96: 243-251, doi: 10.1016/j.wneu.2016.08.087, indexed in Pubmed: 27586179.

4. Pandey N, John S. Kayser-Fleischer Ring. Ncbi.nIm.nih.gov. 2018. https://www.ncbi.nlm.nih.gov/books/NBK459187/ (30 October 2018).

5. Weng SF, Jan RL, Chang C, et al. Risk of Band Keratopathy in Patients with End-Stage Renal Disease. Sci Rep. 2016; 6: 28675, doi: 10.1038/srep28675, indexed in Pubmed: 27346848.

6. Toyka KV. Ptosis in myasthenia gravis: extended fatigue and recovery bedside test. Neurology. 2006; 67(8): 1524, doi: 10.1212/01. wnl.0000240069.24338.c8, indexed in Pubmed: 17060601.
7. Kanagalingam S, Miller NR. Horner syndrome: clinical perspectives. Eye Brain. 2015; 7: 35-46, doi: 10.2147/EB.S63633, indexed in Pubmed: 28539793.

8. Pearce J. The Marcus Gunn pupil. J Neurol Neurosurg Psychiatry. 1996; 61(5): 520, doi: 10.1136/jnnp.61.5.520, indexed in Pubmed: 8937350.

9. Kelly CA, Upex A, Bateman DN, et al. Neurological assessment of coma. J Neurol Neurosurg Psychiatry. 2001; 71 Suppl 1(2): i13-i17, doi: 10.1136/jnnp.71.suppl_1.i13, indexed in Pubmed: 11511736.

10. Raza HK, Chen H, Chansysouphanthong T, et al. The aetiologies of the unilateral oculomotor nerve palsy: a review of the literature. Somatosens Mot Res. 2018; 35(3-4): 229-239, doi: 10.1080/08990220.2018.1547697, indexed in Pubmed: 30592440.

11. Morillon P, Bremner F. Trochlear nerve palsy. Br J Hosp Med (Lond). 2017; 78(3): C38-C40, doi: 10.12968/hmed.2017.78.3.C38, indexed in Pubmed: 28277775.

12. Virgo JD, Plant GT. Internuclear ophthalmoplegia. Pract Neurol. 2017; 17(2): 149-153, doi: 10.1136/practneurol-2016-001428, indexed in Pubmed: 27927777.

13. Bae Y, Kim J, Choi B, et al. Brainstem Pathways for Horizontal Eye Movement: Pathologic Correlation with MR Imaging. RadioGraphics. 2013;33(1):47-59.Virgo J, Plant G. Internuclear ophthalmoplegia. Practical Neurology. 2016; 17(2): 149-153.

14. Fruhmann Berger M, Pross RD, Ilg UJ, et al. Deviation of eyes and head in acute cerebral stroke. BMC Neurol. 2006; 6: 23, doi: 10.1186/1471-2377-6-23, indexed in Pubmed: 16800885.

15. Brandt TH, Dieterich M. Different types of skew deviation. J Neurol Neurosurg Psychiatry. 1991; 54(6): 549-550, doi: 10.1136/ jnnp.54.6.549, indexed in Pubmed: 1880519.

16. Han WG, Yoon HC, Kim TM, et al. Clinical Correlation between Perverted Nystagmus and Brain MRI Abnormal Findings. J Audiol Otol. 2016; 20(2): 85-89, doi: 10.7874/jao.2016.20.2.85, indexed in Pubmed: 27626081.

17. Strupp M, Hüfner K, Sandmann R, et al. Central Oculomotor Disturbances and Nystagmus. Deutsches Aerzteblatt Online. 2011, doi 10.3238/arztebl.2011.0197.

18. Hoehn ME, Calderwood J, O'Donnell T, et al. Children with dorsal midbrain syndrome as a result of pineal tumors. J AAPOS. 2017; 21(1): 34-38, doi: 10.1016/j.jaapos.2016.09.024, indexed in Pubmed: 28069468.

19. Wong A. An update on opsoclonus. Curr Opin Neurol. 2007; 20(1): 25-31, doi: 10.1097/WC0.0b013e3280126b51, indexed in Pubmed: 17215685

20. Mehler MF. The clinical spectrum of ocular bobbing and ocular dipping. J Neurol Neurosurg Psychiatry. 1988; 51(5): 725-727, doi: 10.1136/jnnp.51.5.725, indexed in Pubmed: 3404172.

21. Prakash S, Dumoulin SO, Fischbein N, et al. Congenital achiasma and see-saw nystagmus in VACTERL syndrome. J Neuroophthalmol. 2010; 30(1): 45-48, doi: 10.1097/WNO.0b013e3181c28fc0, indexed in Pubmed: 20182207.

22. Rudge $P$, Leech J. Analysis of a case of periodic alternating nystagmus. J Neurol Neurosurg Psychiatry. 1976; 39(4): 314-319, doi: 10.1136/ jnnp.39.4.314, indexed in Pubmed: 932748.

23. Arumugam J, Vijayalakshmi AM. Metoclopramide-induced oculogyric crisis presenting as encephalitis in a young girl. Indian J Pharmacol. 2012; 44(2): 266-267, doi: 10.4103/0253-7613.93867, indexed in Pubmed: 22529490.

24. William W. Campbell. The Ocular Motor Nerves. DeJong's The Neurologic Examination, Sixth Edition. Lippincott Williams \& Wilkins. 2005: 149-190. 
25. William W. Campbell. The Acoustic (Vestibulocochlear) Nerve. DeJong's The Neurologic Ex-amination, Sixth Edition. Lippincott Williams \& Wilkins. 2005: 227-249.

26. José Biller, Gregory Gruener, Paul W. Brazis. Examination of the Peripheral Ocular Motor Sys-tem. DeMyer's The Neurologic Examination, A Programmed Text, Sixth Edition. The McGraw-Hill Companies, Inc. 2009: 125-170.

27. José Biller, Gregory Gruener, Paul W. Brazis. Examination of the Central Ocular Motor System. DeMyer's The Neurologic Examination, A Programmed Text, Sixth Edition. The McGraw-Hill Companies, Inc. 2009: 175-196.

28. Paul W. Brazis, Jose C. Masdeu, Jose Biller. The Localization of Lesions Affecting the Ocular Motor System. Localization in Clinical Neurology, Fifth Edition. Lippincott Williams. 2007: 169-250.

29. Fisher CM. Some neuro-ophthalmological observations. J Neurol Neurosurg Psychiatry. 1967; 30(5): 383-392, doi: 10.1136/ jnnp.30.5.383, indexed in Pubmed: 6062990.
30. Restel M, Graban A, Witkowski G, et al. Midbrain and bilateral paramedian thalamic stroke due to artery of Percheron occlusion. Neurol Neurochir Pol. 2016; 50(3): 180-184, doi: 10.1016/j.pjnns.2016.01.008, indexed in Pubmed: 27154444.

31. Rajska K, Rożniecki J, Loba P, et al. Total ocular akinesis: Miller Fisher or Guillain-Barré syndrome? Neurol Neurochir Pol. 2011; 45(3): 297-300, doi: 10.1016/s0028-3843(14)60083-9, indexed in Pubmed: 21866487.

32. Paprocka J, Jamroz E. [Joubert syndrome and related disorders]. Neurol Neurochir Pol. 2012; 46(4): 379-383, doi: 10.5114/ ninp.2012.30457, indexed in Pubmed: 23023437.

33. Gogol P, Gogol A, Opuchlik A, et al. Paraneoplastic brainstem encephalomyelitis and atypical form of chronic inflammatory demyelinating polyneuropathy in patient with testicular germinal tumor-is this an overlap syndrome? a case report. Neurol Neurochir Pol. 2015; 49(2): 129-133, doi: 10.1016/j.pjnns.2015.01.006, indexed in Pubmed: 25890929. 